\title{
Exchange Characteristics of Lead, Zinc, and Cadmium in Selected Tropical Soils
}

\author{
Tope O. Bolanle-Ojo, ${ }^{1}$ Abiodun D. Joshua, ${ }^{2}$ Opeyemi A. Agbo-Adediran, ${ }^{3}$ \\ Ademola S. Ogundana, ${ }^{3}$ Kayode A. Aiyeyika, ${ }^{1}$ Adebisi P. Ojo, ${ }^{1}$ \\ and Olubunmi O. Ayodele ${ }^{1}$ \\ ${ }^{1}$ Forestry Research Institute of Nigeria, P.M.B. 5054, Ibadan 234-02, Oyo State, Nigeria \\ ${ }^{2}$ Federal College of Wildlife Management, P.M.B. 268, New Bussa 234-02, Niger State, Nigeria \\ ${ }^{3}$ Federal College of Forestry, P.M.B. 5054, Ibadan 234-02, Oyo State, Nigeria \\ Correspondence should be addressed to Olubunmi O. Ayodele; bayodele2002@gmail.com
}

Received 31 July 2013; Revised 17 October 2013; Accepted 4 November 2013; Published 16 January 2014

Academic Editor: Silvia Imhoff

Copyright (C) 2014 Tope O. Bolanle-Ojo et al. This is an open access article distributed under the Creative Commons Attribution License, which permits unrestricted use, distribution, and reproduction in any medium, provided the original work is properly cited.

Conducting binary-exchange experiments is a common way to identify cationic preferences of exchangeable phases in soil. Cation exchange reactions and thermodynamic studies of $\mathrm{Pb}^{2+} / \mathrm{Ca}^{2+}, \mathrm{Cd}^{2+} / \mathrm{Ca}^{2+}$, and $\mathrm{Zn}^{2+} / \mathrm{Ca}^{2+}$ were carried out on three surface $(0-$ $30 \mathrm{~cm}$ ) soil samples from Adamawa and Niger States in Nigeria using the batch method. The physicochemical properties studies of the soils showed that the soils have neutral $\mathrm{pH}$ values, low organic matter contents, low exchangeable bases, and low effective cation exchange capacity (mean: $3.27 \mathrm{cmolc} \mathrm{kg}{ }^{-1}$ ) but relatively high base saturations ( $\gg 50 \%$ ) with an average of $75.9 \%$. The amount of cations sorbed in all cases did not exceed the soils cation exchange capacity (CEC) values, except for Pb sorption in the entisol-AD2 and alfisol-AD3, where the $\mathrm{CEC}$ were exceeded at high $\mathrm{Pb}$ loading. Calculated selectivity coefficients were greater than unity across a wide range of exchanger phase composition, indicating a preference for these cations over $\mathrm{Ca}^{2+}$. The $K_{\mathrm{eq}}$ values obtained in this work were all positive, indicating that the exchange reactions were favoured and equally feasible. These values indicated that the $\mathrm{Ca}$ /soil systems were readily converted to the cation/soil system. The thermodynamic parameters calculated for the exchange of these cations were generally low, but values suggest spontaneous reactions.

\section{Introduction}

Baseline concentration of heavy metals in soils depends on the local geology. This has been supplemented to various degrees by anthropogenic inputs from industrial processes and operations that generate wastes containing considerable amounts of these metals. Heavy metals are nonbiodegradable and hence environmentally persistent and may accumulate in biota and the soils where they can affect soil properties. They interact with soils in various ways but sorption from aqueous solution onto solid particles is an important process that influences their accumulation and transport in the environment [1]. Thus, heavy metals pollution in soils has become a significant topic of concern.

Nowhere has the situation become more serious than in developing countries due to the recent establishment of industries producing wastes and effluents containing heavy metals. This has led to increase in the heavy metal burden of the developing countries where waste management practices are poor and the final metal sink is the soil. Metals may interact with soils in many ways: they may be sorbed by the soil depending on the soil $\mathrm{pH}$, organic matter content, cation exchange capacity, and so forth; the oxidation state of some metals may be changed, thus affecting their mobility, bioavailability, and toxicity [1]. Our major concern is however the displacement of the major exchangeable cations, $\mathrm{Ca}, \mathrm{Na}$ and $\mathrm{K}$, by toxic heavy metals, thus increasing their chances of absorption by plants and consequently man via the food chain [2].

Furthermore, due to the selective retention and competitive adsorption by the soil, there is the tendency of increasing the concentration of these elements in the soil 
beyond tolerable limits. Thus, the movement of these metals into the food chain may be enhanced with possible deleterious effects on human health and ecological balance [3, 4]. Therefore, understanding and minimizing soil pollution and degradation is of fundamental importance and deserves the highest priority in order to protect our food supplies from toxic substances which can accumulate in the soil. Understanding how these cations compete for exchange sites in soils, at varying concentrations and saturations on the exchanger relative to a typical cation (e.g., Ca), would provide useful information about their selectivities and, thus, mobility in soils. Equilibrium thermodynamic studies were used to explain the behaviour of cations in soils, and data obtained from the studies can then be applied not only to predict which of the soil processes are likely to occur, but also to estimate the solution metal composition at equilibrium since the aqueous fractions are of primary importance when considering the migration potentials of metals associated with soils.

$\mathrm{Cd}$ and $\mathrm{Pb}$ belong to the most potentially toxic heavy metals. Classified as soluble and strongly hydrating cations, both metals are particularly toxic to plants and higher animals, producing kidney and blood diseases among other health disorders [5]. The ever increasing use of $\mathrm{Zn}$ in many products is assuming a frightening dimension as scientists are showing proofs of harmful effects on living things of high concentration of $\mathrm{Zn}$ [1]. The presence of these cations in soils can affect the plant intake of major cations $(\mathrm{Ca}, \mathrm{Mg}$, and $\mathrm{Na}$ ) which are adsorbed primarily by cation exchange, a readily reversible sorption mechanism caused by electrostatic attraction of cations to negatively charged surfaces [6]. Thus, we have done adsorption of these metals from binary metal solutions using three soils representative of the entisol and alfisol soil groups [7] so as to understand the mobility of these metals in soil in the presence of other metals.

\section{Materials and Methods}

2.1. Soil Sampling, Pretreatment, and Characterization. Three surface $(0-30 \mathrm{~cm})$ soil samples were obtained from Adamawa and Niger States of Nigeria (Table 1). The samples were air dried, crushed gently, and sieved through a 230-mesh size sieve, and fine particles were retained for the study. The soils' $\mathrm{pH}$ was determined in deionized water and $1.0 \mathrm{M}$ $\mathrm{KCl}$ (in ratio $1: 1$ ). Particle size determination was by the hydrometer method [8], organic carbon was by the WalkleyBlack wet digestion method [9], cation exchange capacity (CEC) was by the $1.0 \mathrm{M}$ ammonium acetate $\left(\mathrm{NH}_{4} \mathrm{OAC}\right)$ method at $\mathrm{pH} 7.0$ from the extractable bases: $\mathrm{Na}$ and $\mathrm{K}[10]$, and exchangeable $\mathrm{Ca}$ and $\mathrm{Mg}$ were determined from $1.0 \mathrm{M}$ sodium acetate extracts at pH 7.0 [11]. Total nitrogen, base saturation, exchangeable acidity, exchangeable micronutrients, and trace heavy metals were also determined [12]. Elements in the extracts were determined using the Buck Scientific 205 Atomic Absorption Spectrometer (AAS).

2.2. Preparation of $\mathrm{Ca}$ Homoionic Saturated Soils. About $100 \mathrm{~g}$ each of the samples was first suspended in $1.0 \mathrm{M}$ $\mathrm{NH}_{4} \mathrm{OAc}$ for 2 hours to obtain the $\mathrm{NH}_{4}{ }^{+}$-saturated soils.
TABLE 1: Sample description.

\begin{tabular}{lccc}
\hline $\begin{array}{l}\text { Location/sample } \\
\text { collection point }\end{array}$ & Sample code & Soil class & Coordinate \\
\hline $\begin{array}{l}\text { Along River Benue } \\
\text { Bank }\end{array}$ & AD2 & Entisol & $9^{\circ} 20^{\prime} \mathrm{N} ; 12^{\circ} 30^{\prime} \mathrm{E}$ \\
\hline $\begin{array}{l}\text { Girei Local } \\
\text { Government Area }\end{array}$ & AD3 & Alfisol & $9^{\circ} 20^{\prime} \mathrm{N} ; 12^{\circ} 30^{\prime} \mathrm{E}$ \\
\hline New Bussa & NB & Alfisol & $9^{\circ} 53^{\prime} \mathrm{N} ; 4^{\circ} 31^{\prime} \mathrm{E}$ \\
\hline
\end{tabular}

These were filtered, dried at $105^{\circ} \mathrm{C}$, and then resuspended in $1.0 \mathrm{M} \mathrm{CaCl}_{2}$ solution, mechanically agitated gently for 45 minutes, and left to stand overnight with periodic mechanical agitation. After 16 hours, the suspensions were then filtered under suction and washed with fresh $100 \mathrm{~mL}$ of the saturating solution. The Ca-saturated soils were then washed with $400 \mathrm{~mL}$ of deionized water in $100 \mathrm{~mL}$ potions and then equilibrated for a further 72 hours. After this, the soils were each filtered and washed first with $100 \mathrm{~mL} \mathrm{CaCl}$ solution, then $200 \mathrm{~mL}$ deionized water, and with about $350 \mathrm{~mL}$ ethanol, all in $100 \mathrm{~mL}$ portions until free from chloride [13]. The soils were then transferred into Petri dishes, dried in an oven at $105^{\circ} \mathrm{C}$ for about 5 hours, homogenized, and then stored for $\mathrm{Ca} / \mathrm{Pb}, \mathrm{Ca} / \mathrm{Cd}$, and $\mathrm{Ca} / \mathrm{Zn}$ exchange studies as appropriate.

2.3. Preparation of Equilibrating Solutions. Equilibrating solutions were prepared by using six predetermined mole fractions of the metal $\left(\mathrm{M}^{2+}\right)$. Mole fractions ranged from 0.0 to 1.0 , while maintaining a constant ionic strength of 0.003 . The concentrations were prepared by transferring accurately $0 / 30$, $20 / 24,40 / 18,60 / 12,80 / 6$, and $100 / 0 \mathrm{~mL}$ volumes of $0.01 \mathrm{M}$ $\mathrm{M}^{2+} \mathrm{Cl}_{2} / 0.01 \mathrm{M} \mathrm{CaCl}_{2}$, respectively, into six 1-litre standard flasks and diluted to mark with deionized $\mathrm{H}_{2} \mathrm{O}$ [14]. $\mathrm{NaNO}_{3}$ was used as the indifferent electrolyte.

2.4. Batch Equilibration Method. Replicate batch equilibrations were achieved by adding $50 \mathrm{~mL}$ of equilibrating solution to $1.0 \mathrm{~g}$ of Ca-saturated soil in $120 \mathrm{~mL}$ polypropylene tubes and intermittently shaking the capped bottles mechanically at room temperature $\left(26 \pm 2^{\circ} \mathrm{C}\right)$ for 24 hours. The suspensions were then filtered and the supernatant retained for the estimation of $\mathrm{Ca}, \mathrm{Pb}, \mathrm{Zn}$, and Cd using the Buck Scientific 205 AAS with air-acetylene flame on absorbance mode. The same procedure was repeated at $60^{\circ} \mathrm{C}$ in an incubator maintained at $60 \pm 2^{\circ} \mathrm{C}$ for 24 hours. All experiments were done, in duplicate and in all cases, the experimental errors were $<1 \%$.

\subsection{Data Treatment}

2.5.1. Exchange Calculations. Equation (1) will be used for representative illustration for $\mathrm{Ca} / \mathrm{Pb}$ exchange reaction

$$
\mathrm{Ca}_{(s)}^{2+}+\mathrm{Pb}_{(\mathrm{aq})}^{2+} \rightleftharpoons \mathrm{Ca}_{(\mathrm{aq})}^{2+}+\mathrm{Pb}_{(s)}^{2+}
$$

The concentration of the ions in the adsorbed phases, in mmol kg ${ }^{-1}$, was calculated from the difference between the total ion before and after equilibration. Equilibrium data obtained for the soils at $30^{\circ} \mathrm{C}$ and $60^{\circ} \mathrm{C}$ were used to calculate the 
relative amounts of $\mathrm{Pb}^{2+}$ and $\mathrm{Ca}^{2+}$ ions in solution (as mole fraction of $\mathrm{Pb}^{2+}=\mathrm{XPb}^{2+}$ ) and those of the soil phase (as equivalent fraction of $\mathrm{Pb}^{2+}=X^{\prime} \mathrm{Pb}^{2+}$ ) at equilibrium. Hence, the equivalent ratios of $\mathrm{Ca}^{2+}$ and $\mathrm{Pb}^{2+}$ in both phases were calculated from the following relationships:

$$
\begin{aligned}
& X_{\mathrm{Ca}^{2+}}^{\prime}=\frac{\left[\mathrm{Ca}^{2+}\right]^{\prime}}{\left(\left[\mathrm{Ca}^{2+}\right]^{\prime}+\left[\mathrm{Pb}^{2+}\right]^{\prime}\right)}, \\
& X_{\mathrm{Pb}^{2+}}^{\prime}=\frac{\left[\mathrm{Pb}^{2+}\right]^{\prime}}{\left(\left[\mathrm{Pb}^{2+}\right]^{\prime}+\left[\mathrm{Ca}^{2+}\right]^{\prime}\right)}, \\
& X_{\mathrm{Ca}^{2+}}=\frac{\left[\mathrm{Ca}^{2+}\right]}{\left(\left[\mathrm{Ca}^{2+}\right]+\left[\mathrm{Pb}^{2+}\right]\right)}, \\
& X_{\mathrm{Pb}^{2+}}=\frac{\left[\mathrm{Pb}^{2+}\right]}{\left(\left[\mathrm{Pb}^{2+}\right]+\left[\mathrm{Ca}^{2+}\right]\right)},
\end{aligned}
$$

where $\left[\mathrm{Ca}^{2+}\right]^{\prime}$ and $\left[\mathrm{Pb}^{2+}\right]^{\prime}$ are equivalent concentrations of $\mathrm{Ca}$ and $\mathrm{Pb}$ in the soil phase while $\left(\left[\mathrm{Ca}^{2+}\right]^{\prime}+\left[\mathrm{Pb}^{2+}\right]^{\prime}\right)$ is the total equivalent concentration of the cations, $\mathrm{Ca}$ and $\mathrm{Pb}$, in the soil phase. $\left[\mathrm{Ca}^{2+}\right],\left[\mathrm{Pb}^{2+}\right]$, and $\left(\left[\mathrm{Ca}^{2+}\right]+\left[\mathrm{Pb}^{2+}\right]\right)$ are the corresponding values in solution and $X_{\mathrm{Pb}^{2+}}$ and $X_{\mathrm{Ca}^{2+}}$ are equivalent fractions of the exchanging $\mathrm{Pb}^{2+}$ and $\mathrm{Ca}^{2+}$ in the soil phase.

\subsubsection{Exchange Selectivity Coefficients and Other Thermody-} namic Constants. The exchange selectivity coefficients $\left(K_{c}\right)$ were calculated according to Gaines and Thomas [15] (equation (9)), where $\mathrm{M}^{2+}$ and Ca-soil refer to bivalent and the soil phase metals, respectively,

$$
M_{\mathrm{aq}}^{2+}+\mathrm{Ca}-\mathrm{Soil} \rightleftharpoons M-\mathrm{Soil}+\mathrm{Ca}_{\mathrm{aq}}^{2+}
$$

The selectivity coefficient $K_{c}$ has been defined [16] as

$$
K_{c}=\frac{M_{\mathrm{Ca}^{2+}} \cdot X_{\mathrm{Pb}^{2+}} \cdot \gamma_{\mathrm{Ca}^{2+}}}{M_{\mathrm{Pb}^{2+}} \cdot X_{\mathrm{Ca}^{2+}} \cdot \gamma_{\mathrm{Pb}^{2+}}}
$$

where $M_{\mathrm{Ca}^{2+}}$ and $M_{\mathrm{Pb}^{2+}}$ are the molarity of cations $\left(\mathrm{Ca}^{2+}\right.$ and $\left.\mathrm{Pb}^{2+}\right)$ in equilibrium. $X_{\mathrm{Pb}^{2+}}$ and $X_{\mathrm{Ca}^{2+}}$ are the same as above. The activity coefficients, $\gamma_{x}$, are calculated from the modified Debye-Huckel law [17] in the following:

$$
\log \gamma_{x}=A Z_{x}^{2}\left\{\frac{\sqrt{I}}{(1+\sqrt{I})}-0.3 I\right\},
$$

where $Z_{x}$ is the ion valence, $A$ is a temperature dependent constant, which is obtained from the literature as 0.5141 and 0.5471 per unit volume of solution at $30^{\circ} \mathrm{C}$ and $60^{\circ} \mathrm{C}$, respectively, $\gamma_{x}$ could be either $\gamma_{\mathrm{Ca}^{2+}}$ or $\gamma_{\mathrm{Pb}^{2+}}$, and $I$ is the ionic strength of the solution. In this work, $I$ is fixed at 0.003 . Usually, $\gamma_{x}$ for metals of the same valence is equal and thus has been calculated for the divalent cations used as 1.2733 at $30^{\circ} \mathrm{C}$ and 1.2932 at $60^{\circ} \mathrm{C}$.
Equilibrium constants in this study were obtained by integrating the cation selectivity coefficients over the whole range of exchange isotherm and so may be interpreted in terms of the overall preference of an exchanger for one out of a pair of exchangeable ions:

$$
\text { In } K_{\mathrm{eq}}=-\left(Z_{1-} Z_{2}\right)+\int_{0}^{1} \operatorname{In} K_{c} d \bar{X}_{M} .
$$

Since both exchanging cations are bivalent, $\left(Z_{1-} Z_{2}\right)$ gives zero and thus (9) becomes

$$
\text { In } K_{\mathrm{eq}}=\int_{0}^{1} \operatorname{In} K_{c} d \bar{X}_{M} .
$$

$X_{M}$ is the equivalent fraction of cation on the exchanger; $K_{\mathrm{eq}}$ is the equilibrium constant.

To obtain In $K_{\text {eq, }}$ the integral term of (10) above is evaluated graphically:

$$
\begin{gathered}
\operatorname{In} K_{\mathrm{eq}}=x \operatorname{In} K_{c}+C, \\
\operatorname{In} K_{c}=\left(\frac{1}{x}\right) \operatorname{In} K_{\mathrm{eq}}-\left(\frac{C}{x}\right),
\end{gathered}
$$

where $\operatorname{In} K_{\text {eq }}$ is the slope and $C / x$ is the intercept.

Once the In $K_{\mathrm{eq}}$ was obtained, the Gibbs free energy $\left(\Delta G^{\circ}\right), \Delta H^{\circ}$, and $\Delta S$ values for the exchanger reaction (at a specified temperature, $T$ ) can be computed from the following:

$$
\begin{gathered}
\Delta G^{\circ}=-R T \operatorname{In} K_{\mathrm{eq}}, \\
\Delta G^{\circ}=\Delta H^{\circ}-T \Delta S^{\circ}, \\
\operatorname{In}\left(\frac{K_{2}}{K_{1}}\right)=\left(\frac{\Delta H^{\circ}}{R}\right)\left\{T_{2}^{-1}-T_{1}^{-1}\right\},
\end{gathered}
$$

where $\Delta H$ is the enthalpy change, measured in kilojoules per mole, $R$ is the gas constant, $T_{1}$ and $T_{2}$ are the lower and higher absolute temperatures, and $K_{1}$ and $K_{1}$ are the equilibrium constants at $T_{1}$ and $T_{2}$, respectively.

\section{Results and Discussion}

3.1. Soil Properties. The samples and their physicochemical characteristics are shown in Tables 1 and 2. The soils have been classified as entisol (AD2) and alfisols (AD3 and NB-); however, particle size distributions showed that textural classes for $\mathrm{AD} 2, \mathrm{AD} 3$, and $\mathrm{NB}$ are loam, loamy sand, and sandy loam, respectively [7]. The $\mathrm{pH}$ of the soils measured in both $1: 1$ deionized water and $1.0 \mathrm{M} \mathrm{KCl}$ showed that the soils can be classified as neutral. A value of $\approx 1.0$ for $\Delta \mathrm{pH}$ was observed in the soils $\left(\mathrm{pH}_{\mathrm{KCl}}-\mathrm{pH}_{\mathrm{H}_{2} \mathrm{O}}\right)$ indicating that a slight negative charge is present in each soil as $\mathrm{H}^{+}$and $\mathrm{OH}-$ interact with the soils' surface. These $\mathrm{pH}$ values were within the range found for mineral soils in typical Tropical Nigeria soils $[13,18]$.

The percentage soil organic carbon contents for $\mathrm{AD} 2$ (3.81) and $\mathrm{NB}$ (2.82) are high while those of AD3 (1.15) are 
TABLE 2: Physicochemical properties of the soil samples.

\begin{tabular}{lcccccccccccccc}
\hline \multirow{2}{*}{ Sample } & \multicolumn{2}{c}{$\mathrm{pH}$} & \multicolumn{3}{c}{ Org. C } & \multicolumn{2}{c}{$\mathrm{T} . \mathrm{N}$} & \multicolumn{3}{c}{ Exchangeable bases $\left(\mathrm{cmolc} \mathrm{kg}^{-1}\right)$} & \multicolumn{2}{c}{ CEC } & \multicolumn{3}{c}{ Base sat. } & \multicolumn{3}{c}{ Particle size analysis (\%) } \\
& $\mathrm{KCl}$ & $\mathrm{H}_{2} \mathrm{O}$ & $\%$ & $\%$ & $\mathrm{Ca}$ & $\mathrm{Mg}$ & $\mathrm{Na}$ & $\mathrm{K}$ & $\mathrm{Meq} / 100 \mathrm{~g}$ & $\%$ & Sand & Silt & Clay \\
\hline $\mathrm{AD} 2$ & 6.6 & 7.6 & 3.8 & 0.5 & 1.5 & 0.8 & 0.1 & 0.2 & 3.6 & 71.8 & 51.2 & 31.4 & 17.4 \\
$\mathrm{AD} 3$ & 5.7 & 6.7 & 1.2 & 0.3 & 1.6 & 0.7 & 0.1 & 0.2 & 3.6 & 72.2 & 81.2 & 11.4 & 7.4 \\
$\mathrm{NB}$ & 6.5 & 7.4 & 2.8 & 0.4 & 1.4 & 0.7 & 0.1 & 0.2 & 2.9 & 79.5 & 53.2 & 27.4 & 19.2 \\
\hline
\end{tabular}

Org. C: organic carbon; T. N.: total nitrogen; CEC: cation exchange capacity; Base sat.: base saturation.

described as medium [19] with sequence: AD3 $<$ NB $<$ AD2. Olu-Owolabi et al. [18] and Igwe et al. [20] have reported organic carbon contents of similar range for soils in the West African savannah. The relatively high organic matter content value of $\mathrm{AD} 2$ and $\mathrm{NB}$ may not be unrelated to the rich deposit of organic materials brought inland by tidal action from the rivers Benue and Niger, respectively.

Sum of exchangeable bases for samples AD2 (2.6 cmolc kg $\left.{ }^{-1}\right)$, AD3 (2.6 cmolc kg $\left.{ }^{-1}\right)$, and NB $\left(2.3 \mathrm{cmolc} \mathrm{kg}^{-1}\right)$ (Table 2) are described as low [19]. The sequence of total abundance is $\mathrm{NB}<\mathrm{AD} 2<\mathrm{AD}$. All samples showed exchangeable bases abundance in the order $\mathrm{Ca}>\mathrm{Mg}>\mathrm{K}>$ $\mathrm{Na}$. The predominance of $\mathrm{Ca}$ may be a common feature of Nigerian soils $[13,18]$, and this may be linked to the fact that soils in the subhumid regions are majorly dominated by low activity clay minerals and low organic matter content. The soils all have CEC values that can be described as low [19]. These values agree with results obtained from other studies on Nigerian soils $[13,18,19]$. The CEC sequence for these soils is $\mathrm{NB}<\mathrm{AD} 2<\mathrm{AD} 3$.

3.2. Selectivity Coefficient $\left(K_{c}\right)$. The selectivity coefficient, $K_{c}$, quantifies the preference of the adsorbent for a given cation from a pair, exchanging at its surface at a given solution ratio [21]. Although it is independent of the total ionic strength of the solution bathing the exchanger [22], it is common experience that this quantity varies with ion composition of the exchanger phase. Generally, but not always, it decreases with increasing saturation of the preference cation on the exchanger surface [23].

Values of the experimentally determined selectivity coefficients for the Ca-cation exchange reactions on all soil samples are shown in Table 3. In the $\mathrm{Ca}^{2+} \rightarrow \mathrm{M}^{2+}$ exchange equilibrium, the $K_{c}$ varied continuously with cationic composition of the soil surfaces. Overall, the selectivity coefficients $\left(K_{c}\right)$ were relatively irregular with most values greater than 1. The values of $K_{c}$ were maximum for intermediate values of $X^{\prime} M$. In the NB soil, the amount of cations adsorbed did not exceed the soil CEC value; but, for $\mathrm{Pb}$ sorption in $\mathrm{AD} 2$ and $\mathrm{AD} 3$ soils, it was exceeded at very high $\mathrm{Pb}$ loading, indicating other $\mathrm{Pb}$ sorption mechanisms in addition to cation exchange (Table 3 ). Selectivity coefficients of the soils varied continuously with their surface cationic composition; thus, the higher the CEC, the higher the cation adsorption. Similar results have been reported by Robbins and Carter [24], Olu-Owolabi et al. [18] for soils in Western Nigeria, Sha'to [13] for soils from the central Nigeria State of Benue, Godfrin et al. [25] for $\mathrm{Ca}^{2+} \rightarrow \mathrm{Zn}^{2+}$ exchange system, Gast
[23], and Angove et al. [26]. Depending on the soil, metal ion type, and concentration, temperature had varying effects on the exchange. Increased temperature favoured $\mathrm{Kc}$ for $\mathrm{Pb}$ adsorption in samples $\mathrm{AD} 2$ and $\mathrm{NB} ; \mathrm{Zn}$ in $\mathrm{AD} 2, \mathrm{NB}$, and $\mathrm{AD} 3$; and $\mathrm{Cd}$ in $\mathrm{AD} 3$. However, increased temperature led to reducing $\mathrm{Kc}$ for $\mathrm{Cd}$ adsorption in $\mathrm{AD} 2$ and $\mathrm{NB}$ and $\mathrm{Pb}$ in AD3. The selectivity coefficient values of this study have shown that all three soils have a higher preference for the risk element than for $\mathrm{Ca}^{2+}$ in the order $\mathrm{Cd}^{2+}>\mathrm{Zn}^{2+}>\mathrm{Pb}^{2+}$. In general, soil sample AD3 had the higher $K_{c}$ values than samples AD2 and NB.

3.3. Equilibrium Constant $\left(K_{e q}\right)$. The $K_{\text {eq }}$ values obtained in this work were all positive, indicating that the exchange reactions were favoured and equally feasible (Table 4). These values indicated that the Ca-soil systems were readily converted to the cation-soil system. The small values of $K_{\mathrm{eq}}$ for the $\mathrm{Ca}^{2+} \rightarrow \mathrm{Pb}^{2+}$ exchange systems in $\mathrm{AD} 2$ and $\mathrm{NB}$ indicated a reluctance of the $\mathrm{Ca}$-soil complex to form the $\mathrm{Pb}$-soil complex. This argument is also supported by the positive $\Delta G$ values for the same soils. Increased temperature had no effect on the $\mathrm{Ca}-\mathrm{Pb}$ system for $\mathrm{NB}$ but led to a slight decrease for $\mathrm{Cd}$ adsorption in all soils and $\mathrm{Pb}$ adsorption in AD3. Slight increases were noticed in $\mathrm{Zn}$ adsorption in AD2, AD3, and $\mathrm{NB}$ and $\mathrm{Pb}$ in $\mathrm{AD} 2$. These slight decreases in $K_{\mathrm{eq}}$ especially for $\mathrm{AD} 3$ indicated ease of exchange for the cations.

3.4. Thermodynamic Equilibrium Parameters $\left(\Delta H^{\circ}, \Delta G^{\circ}\right.$, and $\Delta S^{\circ}$ ). The values of the thermodynamic parameters are shown in Table 4 . The $\Delta H$ values were low and in the range of $0.02-11.64 \mathrm{~kJ} \mathrm{~mol}^{-1}$ with a mean value of $0.65 \mathrm{~kJ} \mathrm{~mol}^{-1}$. These small values of $\Delta H$ imply weak electrovalent bond interactions between soil and metal ions in the exchange process. Similar results have been reported by Sidhu et al. [27] and Sha'ato [13] for central Nigeria soils. These values were not compatible with the formation of strong chemical bonds between exchange sites in soil and metal ions, and the exchange process is likely to be on account of the easy breaking of these weak ionic bond interactions between $\mathrm{Ca}$ and soil exchange sites. These calculated enthalpy values are described as "apparent" because they were comprised of contributions from the energetic effects associated with intrinsic adsorption step and dehydration effects of the metal ions inside the aqueous solution, in addition to any plausible contribution from the physical/chemical changes that the sorption sites might undergo as a result of sorption. 
TABLE 3: Selectivity coefficient, $K_{c}$, as a function of soil phase composition in $\mathrm{Ca}^{2+} \rightarrow \mathrm{M}^{2+}$ exchange at $30^{\circ} \mathrm{C}$ and $60^{\circ} \mathrm{C}$ in the different soils studied.

(a) Selectivity coefficient, $K_{c}$, for soil AD2

\begin{tabular}{lccccc}
\hline \multicolumn{5}{c}{$\mathrm{AD} 2$} \\
$X_{\mathrm{Cd}}^{\prime}$ & $K_{c}$ & $X_{\mathrm{Zn}}^{\prime}$ & $K_{c}$ & $X_{\mathrm{Pb}}^{\prime}$ & $K_{c}$ \\
\hline \multicolumn{5}{c}{$30^{\circ} \mathrm{C}$} \\
0.00 & 0.00 & 0.00 & 0.00 & 0.00 & 0.00 \\
0.30 & 33.05 & 0.43 & 5.54 & 0.46 & 0.67 \\
0.43 & 50.89 & 0.61 & 14.49 & 0.69 & 1.05 \\
0.71 & 19.62 & 0.77 & 10.08 & 0.83 & 1.24 \\
0.86 & 10.30 & 0.91 & 4.14 & 0.93 & 1.35 \\
1.00 & 0.00 & 1.00 & 0.00 & 1.00 & 0.00 \\
\hline & & & $60^{\circ} \mathrm{C}$ & & \\
0.00 & 0.00 & 0.00 & 0.00 & 0.00 & 0.00 \\
0.32 & 23.06 & 0.42 & 5.72 & 0.46 & 0.65 \\
0.42 & 44.26 & 0.57 & 17.88 & 0.68 & 2.03 \\
0.73 & 12.84 & 0.76 & 9.60 & 0.83 & 1.67 \\
0.87 & 7.20 & 0.91 & 3.77 & 0.92 & 2.21 \\
1.00 & 0.00 & 1.00 & 0.00 & 1.00 & 0.00 \\
\hline
\end{tabular}

(b) Selectivity coefficient, $K_{c}$, for soil AD3

\begin{tabular}{cccccc}
\hline \multicolumn{5}{c}{$\mathrm{AD} 3$} \\
$X_{\mathrm{Cd}}^{\prime}$ & $K_{c}$ & $X_{\mathrm{Zn}}^{\prime}$ & $K_{c}$ & $X_{\mathrm{Pb}}^{\prime}$ & $K_{c}$ \\
\hline \multicolumn{5}{c}{$30^{\circ} \mathrm{C}$} \\
0.00 & 0.00 & 0.00 & 0.00 & 0.00 & 0.00 \\
0.18 & 127.48 & 0.40 & 13.37 & 0.43 & 7.57 \\
0.24 & 196.05 & 0.62 & 15.83 & 0.61 & 19.80 \\
0.31 & 219.09 & 0.76 & 14.44 & 0.77 & 13.70 \\
0.73 & 41.83 & 0.88 & 10.82 & 0.89 & 10.75 \\
1.00 & 0.00 & 1.00 & 0.00 & 1.00 & 0.00 \\
\hline & & & & & \\
0.00 & 0.00 & 0.00 & 0.00 & 0.00 & 0.00 \\
0.14 & 356.00 & 0.38 & 24.53 & 0.45 & 2.56 \\
0.31 & 241.90 & 0.58 & 33.68 & 0.64 & 9.30 \\
0.55 & 112.83 & 0.73 & 28.50 & 0.75 & 17.58 \\
0.79 & 44.30 & 0.88 & 13.12 & 0.90 & 7.22 \\
1.00 & 0.00 & 1.00 & 0.00 & 1.00 & 0.00 \\
\hline
\end{tabular}

(c) Selectivity coefficient, $K_{c}$, for soil NB

\begin{tabular}{cccccc}
\hline \multicolumn{5}{c}{$\mathrm{NB}$} \\
$X_{\mathrm{Cd}}^{\prime}$ & $K_{c}$ & $X_{\mathrm{Zn}}^{\prime}$ & $K_{c}$ & $X_{\mathrm{Pb}}^{\prime}$ & $K_{c}$ \\
\hline \multicolumn{5}{c}{$30^{\circ} \mathrm{C}$} \\
0.00 & 0.00 & 0.00 & 0.00 & 0.00 & 0.00 \\
0.34 & 24.06 & 0.42 & 6.03 & 0.46 & 0.18 \\
0.48 & 39.50 & 0.65 & 7.23 & 0.69 & 0.53 \\
0.68 & 24.71 & 0.79 & 7.65 & 0.83 & 1.03 \\
0.88 & 8.50 & 0.92 & 2.64 & 0.93 & 1.00 \\
1.00 & 0.00 & 1.00 & 0.00 & 1.00 & 0.00 \\
\hline
\end{tabular}

(c) Continued.

\begin{tabular}{lccccc}
\hline \multicolumn{5}{c}{$\mathrm{NB}$} \\
$X_{\mathrm{Cd}}^{\prime}$ & $K_{c}$ & $X_{\mathrm{Zn}}^{\prime}$ & $K_{c}$ & $X_{\mathrm{Pb}}^{\prime}$ & $K_{c}$ \\
\hline \multicolumn{5}{c}{$60^{\circ} \mathrm{C}$} \\
0.00 & 0.00 & 0.00 & 0.00 & 0.00 & 0.00 \\
0.36 & 17.64 & 0.41 & 8.44 & 0.46 & 0.13 \\
0.51 & 28.85 & 0.61 & 12.84 & 0.69 & 1.78 \\
0.72 & 16.82 & 0.75 & 11.84 & 0.83 & 1.39 \\
0.88 & 7.22 & 0.91 & 3.68 & 0.93 & 1.23 \\
1.00 & 0.00 & 1.00 & 0.00 & 1.00 & 0.00 \\
\hline
\end{tabular}

The Gibb's free energy $\left(\Delta G^{\circ}\right)$ values were all negative, except for $\mathrm{Pb}$ exchange in $\mathrm{AD} 2$ and $\mathrm{NB}$ suggesting spontaneous reactions (Table 4). Hence, the "soil-heavy cation" complex formation was favoured. The $\mathrm{Ca}^{2+} \rightarrow \mathrm{Pb}^{2+}$ exchange complexes in $\mathrm{AD} 2$ and $\mathrm{NB}$ had positive $\Delta G^{\circ}$ values; this may be due to the uncertainties in the estimation of thermodynamic parameters using linear plots of thermodynamic models which may introduce some errors that could shift values from the border of one extreme to another [28]. When this occurs, adsorption reactions that have small but negative $\Delta G$ could shift to small but positive $\Delta G$ values. This may be the case with the positive $\Delta G$ values obtained in this study, though A. S. Özcan and A. Özcan, [29] have shown that positive values for $\Delta G$ are quite common with ion-exchange mechanism of adsorption of cations. Overall, the sorption data showed that, at equilibrium, the tendency for these soils was towards spontaneous adsorption of the cations in preference to $\mathrm{Ca}^{2+}$. Similar results have been reported by Alvarez-Ayuso and Garcia-Sanchez [30].

The $\Delta S^{\circ}$ values were positive, except for Cd exchange in $\mathrm{AD} 3$ and $\mathrm{NB}$, and $\mathrm{Pb}$ exchange in $\mathrm{AD} 3$, suggesting increased disorder at equilibrium. The positive entropy suggests increased disorder at equilibrium while the negative indicated otherwise. The increased entropy at equilibrium may be due to increase in the dehydration steps of the adsorbate ions, which are known to possess relatively high energies of solvation and thus are stabilized by water sheaths in the absence of the adsorbent. The reverse was the case for $\mathrm{Cd}$ exchange in $\mathrm{AD} 3$ and $\mathrm{NB}$ and for $\mathrm{Pb}$ exchange in AD3. Although positive entropy is theoretically associated with spontaneity, this does not suggest that exchanges with negative entropy were not spontaneous since enthalpy and entropy work to complement one another. These two factors are the major forces leading to the observed spontaneity of the exchange.

\section{Conclusion}

The soils studied in this work can be classified as "strong" acid exchangers because cation exchange was the major sorption mechanism observed. The amount of cations sorbed in most cases did not exceed the CEC values, except for $\mathrm{Pb}$ sorption in AD2 (entisol) and AD3 (alfisol) where it was slightly exceeded at very high $\mathrm{Pb}$ loading, indicating a specific $\mathrm{Pb}$ sorption mechanism in addition to cation exchange. Soil 
TABLE 4: Thermodynamic data for adsorption on samples AD2, AD3, and NB.

\begin{tabular}{|c|c|c|c|c|c|c|}
\hline & $30^{\circ} \mathrm{C} K_{\mathrm{eq}}$ & $60^{\circ} \mathrm{C} K_{\mathrm{eq}}$ & $\Delta G^{\circ}\left(\mathrm{kJ} \mathrm{mol}^{-1}\right)$ at $30^{\circ} \mathrm{C}$ & $\Delta G^{\circ}\left(\mathrm{kJ} \mathrm{mol}^{-1}\right)$ at $60^{\circ} \mathrm{C}$ & $\Delta H^{\circ}\left(\mathrm{kJ} \mathrm{mol}^{-1}\right)$ & $\Delta S^{\circ}\left(\mathrm{JK}^{-1} \mathrm{~mol}^{-1}\right)$ \\
\hline $\mathrm{AD} 2 \mathrm{~Pb}^{2+}$ & 0.85 & 0.90 & 0.4176 & 0.2780 & 1.8288 & 4.66 \\
\hline $\mathrm{AD} 2 \mathrm{Cd}^{2+}$ & 3.47 & 3.39 & -3.1328 & -3.3793 & -0.6431 & 8.22 \\
\hline $\mathrm{AD} 2 \mathrm{Zn}^{2+}$ & 2.72 & 2.84 & -2.5181 & -2.8893 & 1.2303 & 12.37 \\
\hline AD3 $\mathrm{Pb}^{2+}$ & 3.10 & 2.05 & -2.8524 & -1.9828 & -11.6352 & -28.99 \\
\hline $\mathrm{AD} 3 \mathrm{Cd}^{2+}$ & 2.77 & 2.21 & -2.5678 & -2.1924 & -6.3587 & -12.51 \\
\hline $\mathrm{AD} 3 \mathrm{Zn}^{2+}$ & 3.38 & 4.33 & -3.0678 & -4.0590 & 6.9431 & 33.04 \\
\hline $\mathrm{NB} \mathrm{Pb}^{2+}$ & 0.46 & 0.46 & 1.9649 & 2.15730 & 0.0224 & -6.41 \\
\hline $\mathrm{NB} \mathrm{Cd}^{2+}$ & 3.78 & 3.54 & -3.3474 & -3.4979 & -1.8288 & 5.01 \\
\hline $\mathrm{NB} \mathrm{Zn^{2+ }}$ & 2.52 & 2.97 & -2.3259 & -3.0133 & 4.6166 & 22.91 \\
\hline
\end{tabular}

composition played a larger role than metal type in the patterns of selectivity for the cations studied. $\Delta G$ values indicated weak electrovalent bond interactions between the soils and metal ions and reactions were spontaneous and feasible. The soils preferentially adsorbed $\mathrm{Pb}, \mathrm{Zn}$, and $\mathrm{Cd}$ over $\mathrm{Ca}$. AD2 and NB had higher adsorption capacity for these metals because of their higher organic matter and clay contents. These heavy metals in AD3 (Girei) will pose more challenge to biota as well as leach into ground water aquifer due to the reduced adsorptions and high concentrations in soil water solutions. Thus, for a sustainable soil use and development of suitable strategies for proper management of heavy metal soils, soil properties and nature of pollutant must be taken into consideration and thus the impact on environment can be minimized.

\section{Conflict of Interests}

The authors declare that there is no conflict of interests regarding the publication of this paper.

\section{References}

[1] R. P. Tiwari, P. B. Ramudu, R. K. Srivastava, and M. K. Gupta, "Sorption and desorption studies of metallic zinc on an alluvial soil," Iranian Journal of Environmental Health Science and Engineering, vol. 4, no. 3, pp. 139-146, 2007.

[2] S. Dirican, S. Çilek, H. Çiftçi, M. Bıyıkoglu, S. Karaçınar, and A. Yokus, "Preliminary study on heavy metal concentrations of Anatolian Khramulya, Capoeta tinca (Heckel, 1843) from Çamlıgöze Dam Lake, Sivas, Turkey," Journal of Environmental Health Science and Engineering, vol. 11, article 7, 2013.

[3] D. Rais, B. Nowack, R. Schulin, and J. Luster, "Sorption of trace metals by standard and micro suction cups in the absence and presence of dissolved organic carbon," Journal of Environmental Quality, vol. 35, no. 1, pp. 50-60, 2006.

[4] J. J. Stoorvogel and E. M. A. Smaling, "Assessment of soil nutrient depletion in sub-saharan Africa 1983-2000," Report No. 28, Winand Staring Ctr., Wageningen, The Netherlands, 1990.

[5] S. Serrano, F. Garrido, C. G. Campbell, and M. T. GarcíaGonzález, "Competitive sorption of cadmium and lead in acid soils of Central Spain," Geoderma, vol. 124, no. 1-2, pp. 91-104, 2005.
[6] D. L. Sparks, Environmental Soil Chemistry, Academic Press, San Diego, Calif, USA, 2003.

[7] Soil Survey Staff, Keys to Soil Taxonomy, United States Department of Agriculture, Natural Resources Conservation Service, 10th edition, 2006.

[8] P. R. Day, "Particle fractionation and particle size analysis," in Methods of Soil Analysis Part I, C. A. Black, D. D. Evans, J. L. White, L. E. Ensminger, and F. E. Clark, Eds., pp. 545-567, American Society of Agronomy, Madison, Wis, USA, 1965.

[9] A. Walkley and I. A. Black, "An examination of the degtjareff method for soil organic matter and a proposed modification of the chromic acid titration method," Soil Science, vol. 37, pp. 2938, 1934.

[10] H. D. Chapman, "Cation exchange capacity", in Methods of Soil Analysis: Chemical and Microbial Properties, C. A. Black, Ed., vol. 9 of Agronomy Series, pp. 891-901, American Society of Agronomy, 1965.

[11] C. A. Bower, R. F. Reitemeir, and M. Fireman, "Exchangeable cation analysis of saline and alkali soils," Soil Science, vol. 73, pp. 251-261, 1952.

[12] J. J. Benton Jr., Laboratory Guide for Conducting Soil Tests and Plant Analysis, CRC Press, New York, NY, USA, 2001.

[13] H. R. Sha'ato, Physico-chemical and thermodynamic studies of some soils of the lower Benue valley of Nigeria [Ph.D. thesis], University of Ibadan, Ibadan, Nigeria, 1996.

[14] T. M. DeSutter, G. M. Pierzynski, and L. R. Baker, "Flowthrough and batch methods for determining calciummagnesium and magnesium-calcium selectivity," Soil Science Society of America Journal, vol. 70, no. 2, pp. 550-554, 2006.

[15] G. L. Gaines and H. C. Thomas, "Adsorption studies on clay minerals. II. A formulation of the thermodynamics of exchange adsorption," Journal of Chemical Physics, vol. 21, no. 4, pp. 714$718,1953$.

[16] J. A. Marinsky, Ion Exchange. A Series of Advances, Marcel Dekker, New York, NY, USA, 1966.

[17] C. W. Davies, Ion Association, Butterworths, London, UK, 1962.

[18] B. I. Olu-Owolabi, K. O. Adebowale, and O. T. Oseni, "Physicochemical and thermodynamic adsorption studies of a ferric luvisol soil in Western Nigeria," Soil and Sediment Contamination, vol. 19, no. 1, pp. 119-131, 2010.

[19] A. A. Fagbami and E. A. A. Shogunle, "Nigeria: reference soil of the moist lowlands near Ife (Osun State)," Soil Brief Nigeria 3, University of Ibadan and International Soil Reference and Information Centre, Wageningen, The Netherlands, 1995.

[20] C. A. Igwe, F. O. R. Akamigbo, and J. S. C. Mbagwu, "Chemical and mineralogical properties of soils in southeastern Nigeria in 
relation to aggregate stability," Geoderma, vol. 92, no. 1-2, pp. 111-123, 1999.

[21] F. Helferich, Ion Exchange Series in Advanced Chemistry, McGraw Hill, New York, NY, USA, 1962.

[22] G. Sposito, The Thermodynamics of Soil Solutions, Oxford University Press, Oxford, UK, 1981.

[23] R. G. Gast, "Standard free energies of exchange for alkali metal cation on Wyoming Bentonite," Soil Science Society of America Proceedings, vol. 33, pp. 37-41, 1969.

[24] C. W. Robbins and D. L. Carter, "Selectivity coefficients for calcium-magnesium-sodium-potassium exchange in eight soils," Irrigation Science, vol. 4, no. 2, pp. 95-102, 1983.

[25] J. Godfrin, P. Cloos, and R. van Bladel, "Sélectivité des échanges ioniques $\mathrm{Ca}-\mathrm{Cu}$ et $\mathrm{Ca}-\mathrm{Zn}$ dans quelques sols Belgique," Pedologie, vol. 39, pp. 89-110, 1989.

[26] M. J. Angove, B. B. Johnson, and J. D. Wells, “The influence of temperature on the adsorption of cadmium(II) and cobalt(II) on kaolinite," Journal of Colloid and Interface Science, vol. 204, no. 1, pp. 93-103, 1998.

[27] A. S. Sidhu, N. S. Randhawa, and M. K. Sinha, "Adsorption and desorption of zinc in different soils," Soil Science, vol. 124, pp. 211-218, 1977.

[28] E. I. Unuabonah, K. O. Adebowale, B. I. Olu-Owolabi, L. Z. Yang, and L. X. Kong, "Adsorption of $\mathrm{Pb}$ (II) and Cd (II) from aqueous solutions onto sodium tetraborate-modified Kaolinite clay: equilibrium and thermodynamic studies," Hydrometallurgy, vol. 93, no. 1-2, pp. 1-9, 2008.

[29] A. S. Özcan and A. Özcan, "Adsorption of acid dyes from aqueous solutions onto acid-activated bentonite," Journal of Colloid and Interface Science, vol. 276, no. 1, pp. 39-46, 2004.

[30] E. Alvarez-Ayuso and A. Garcia-Sanchez, "Removal of heavy metals from waste waters by natural and Na-exchanged bentonites," Clays and Clay Minerals, vol. 51, pp. 475-480, 2003. 


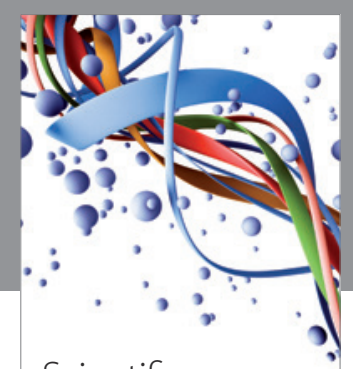

Scientifica
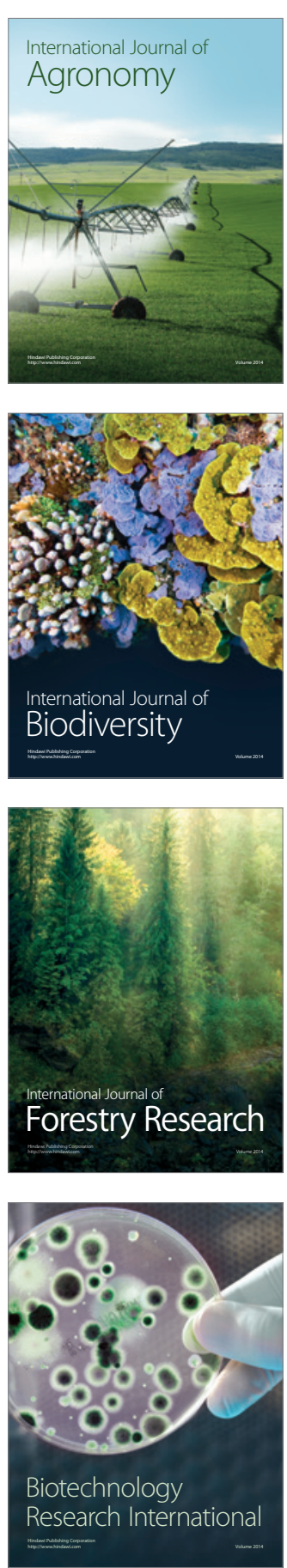
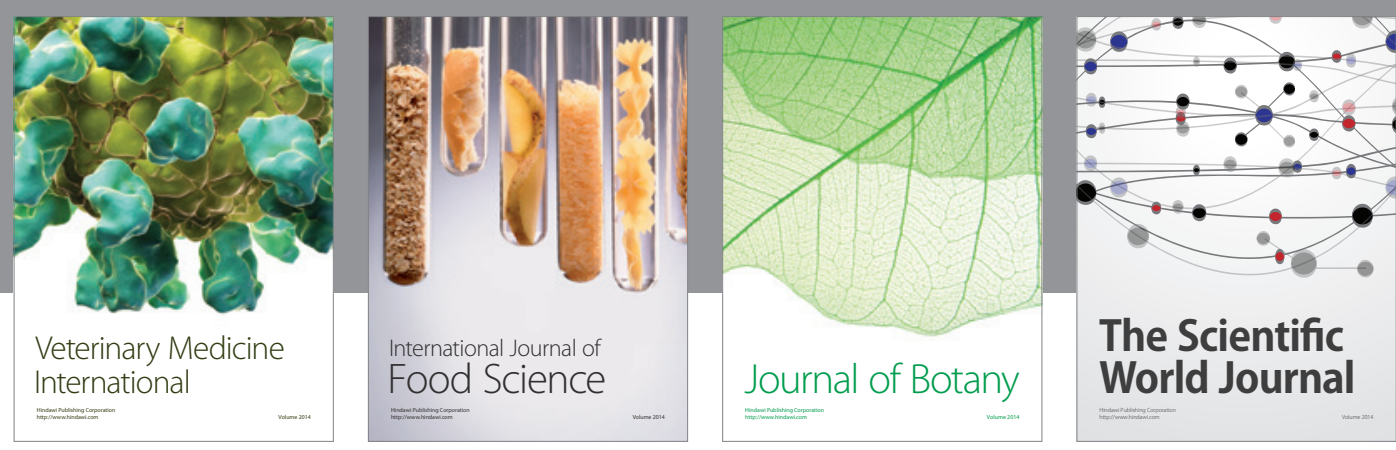

The Scientific World Journal
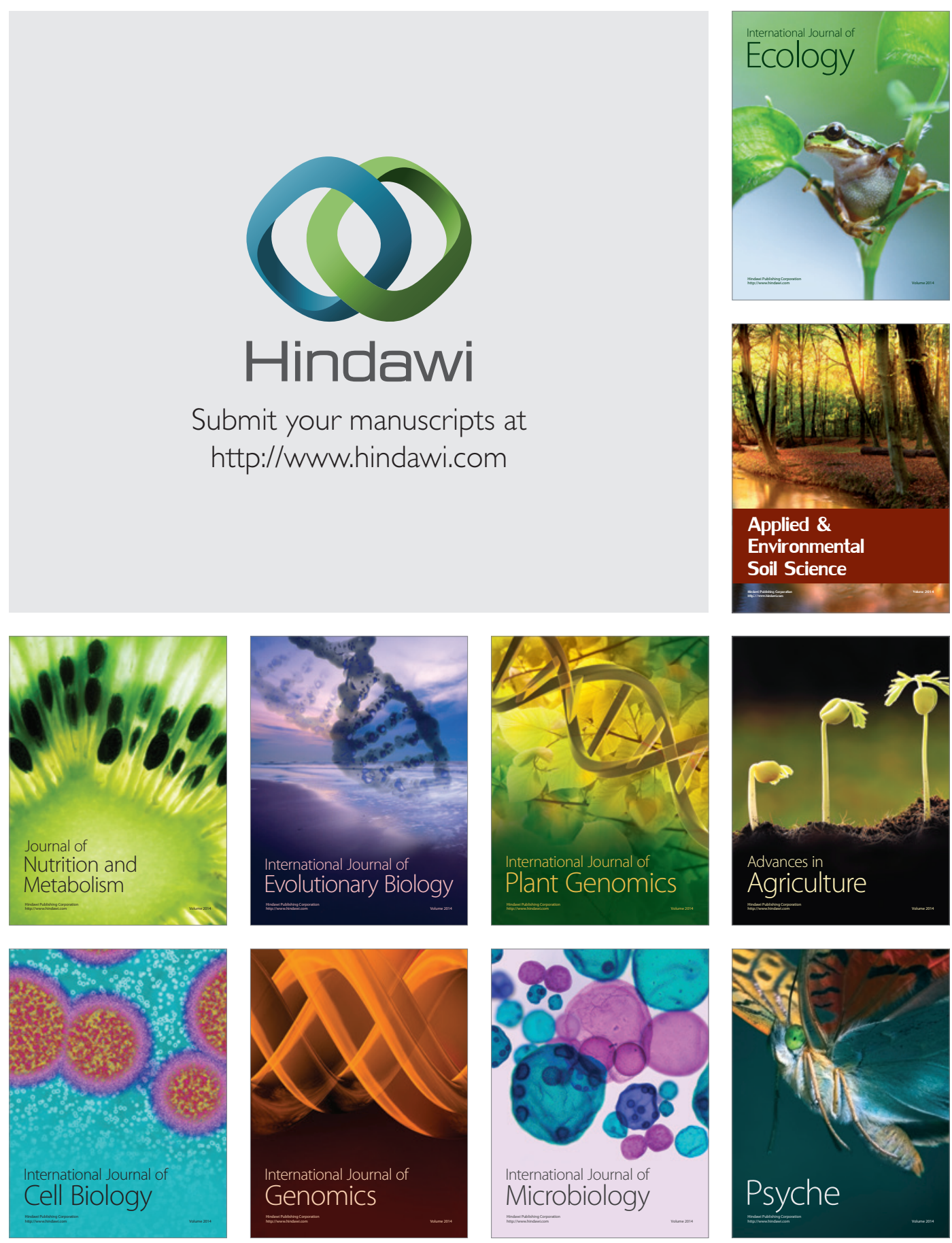